\title{
Are terrestrial isopods able to use stridulation and vibrational communication as forms of intra and interspecific signaling and defense strategies as insects do? A preliminary study in Armadillo officinalis
}

\author{
Sofia Cividini $^{1}$ (D) - Spyros Sfenthourakis ${ }^{2}$ (D) $\cdot$ Giuseppe Montesanto $^{3}$ (D)
}

Received: 13 July 2019 / Revised: 27 October 2019 / Accepted: 31 October 2019 /Published online: 10 December 2019

(C) The Author(s) 2019

\begin{abstract}
The capability of producing sounds and vibrations is well known in insects and is thought to be a form of intra- and interspecific communication. Sounds and vibrations are used and modulated for several aims such as interacting with conspecifics, getting information from the environment, and defending against predators. This phenomenon is less known but also present in other arthropods, including a few roller-type terrestrial isopods. In this study, we used a Y-shape test apparatus to investigate the behavior of adult individuals of Armadillo officinalis Duméril, 1816 (Crustacea: Isopoda: Oniscidea) when exposed to two particular vibrational stimuli, namely species-specific stridulations and non-specific substrate-borne vibrations. Our results showed that adults of $A$. officinalis significantly react to the presence of both types of vibrational stimuli, by moving away from the vibrational source as if they experienced these vibrations as a sign of danger or disturbance. A. officinalis can produce stridulations only when it rolls into a ball during the so-called conglobation, a possible defense mechanism against predators. Stridulation might thus be a secondary form of defense used during conglobation to deter a predator following contact with it and might be experienced as an alert by conspecifics nearby. The high sensitivity to non-specific substrate-borne vibrations might provide A. officinalis with the possibility to anticipate dangers and adverse conditions, giving it a better chance of survival.
\end{abstract}

Keywords Biotremology $\cdot$ Crustacea: Isopoda: Oniscidea $\cdot$ Insects $\cdot$ Vibrational communication

\section{Introduction}

The capability of arthropods to emit sounds and produce vibrations, sometimes within the audible range of frequency for humans, has aroused great interest and curiosity among the scientific community. This phenomenon is well known and

Communicated by: Matthias Waltert

Electronic supplementary material The online version of this article (https://doi.org/10.1007/s00114-019-1656-3) contains supplementary material, which is available to authorized users.

Sofia Cividini

s.cividini1@campus.unimib.it

1 Department of Biostatistics, University of Liverpool, Liverpool, UK

2 Department of Biological Sciences, University of Cyprus, Nicosia, Cyprus

3 Dipartimento di Biologia, Università degli Studi di Pisa, Pisa, Italy studied in insects, but less well known and understudied in terrestrial isopods. Insects can produce sounds and vibrations in different ways using a variety of body structures. These include rubbing two body parts together (stridulation), striking body parts such as feet, head, or abdomen on the substrate (percussion), vibrating some body parts in the air (tremulation), vibrating specific membranes named tymbals, and forcibly ejecting air or fluid (Alexander 1957; Frings and Frings 1958; Ewing 1989; Bailey 1991; Young and BennetClark 1995; Virant-Doberlet and Čokl 2004; Hill 2008; Cocroft et al. 2014). Insects produce and modulate different types of sounds and vibrations according to different situations such as the absence or presence of individuals of the same or different species and for different aims (Alexander 1957; Haskell 1974; Bennet-Clark 1999; Čokl and VirantDoberlet 2003; Cocroft and Rodríguez 2005). Insects generally use species-specific songs to locate and recognize mates and less specific signals to get information on potential dangers, enemies, or rivals (Field and Bailey 1997; Čokl and 
Virant-Doberlet 2003; Cocroft and Rodríguez 2005). In some species of insects (mainly in Orthoptera), adult males always emit the same rhythmical pattern during particular periods of the day to call back females, to lead females to produce sounds in turn to localize them, or to favor aggregation (Alexander 1957; Field and Bailey 1997; Čokl and Virant-Doberlet 2003; Cocroft and Rodríguez 2005). Insects can also produce sounds and surface-borne vibrations in the presence of organisms of different species (e.g., alarm cries, distress calls, protest sounds, congregational sounds) and the same species (e.g., courtship or mating songs, and warnings or fight songs) (Alexander 1957; Masters 1979; Yack et al. 2000; Čokl and Virant-Doberlet 2003; Cocroft and Rodríguez 2005).

Sounds propagate as compressional longitudinal waves through a homogeneous medium such as air or water, and particles oscillate in the same direction as wave propagation (Hill and Wessel 2016). In this kind of communication, studied in bioacoustics, the receiver utilizes the acoustic component inside the mechanical signal to get clues (Hill and Wessel 2016). Another form of communication that has received increasing attention in the last two decades, and which has been especially well-studied in insects, is the communication mediated by surface-borne vibrations. This field of study is known as biotremology (Hill 2001, 2008, 2009; Čokl and Virant-Doberlet 2003; Virant-Doberlet and Čokl 2004; Cocroft and Rodríguez 2005; Cocroft et al. 2014; Hill and Wessel 2016). Unlike sounds, surface-borne vibrations are waves produced at the boundary between two different media. Consequently, particles oscillate perpendicularly to the plane of wave propagation while inside the mechanical signal (Hill and Wessel 2016). In this form of communication, the receiving individual uses the surface-borne component of the mechanical signal to get information using specialized perception organs (Hill and Wessel 2016). This system of communication is thought to be among the most ancient ones. Apart from being used to retrieve information from the environment, it seems to be involved in many adaptive behaviors, such as mating, parental care, foraging, competition, conspecific localization, and danger perception, in both invertebrates and vertebrates (Gogala et al. 1974; Cocroft 1996, 1998, 1999, 2001; Hill 2001, 2008, 2009; Elias et al. 2004; Castellanos and Barbosa 2006; Hebets et al. 2008; Evans et al. 2009; Mazzoni et al. 2009, 2010, 2013, 2014; Caldwell et al. 2010; Cocroft et al. 2014; Hill and Wessel 2016; Howard et al. 2018; Davranoglou et al. 2019). Cocroft (2001) suggested that communication through substrate-borne vibrations might play an important role in herbivorous insects living in groups, assisting them to locate conspecifics and to remain in the group, to find food, and to avoid predation. Caterpillars can distinguish wasps and stink bugs from other predators like birds or other herbivores by differentiating their substrateborne vibrations (Castellanos and Barbosa 2006). Insects like Scaphoideus titanus Ball, 1932 (Hemiptera: Cicadellidae) and
Hyalesthes obsoletus Signoret, 1865 (Hemiptera: Cixiidae) use substrate-borne vibrations to recognize and localize mates (Mazzoni et al. 2009, 2010). In the species of psyllids, Aacanthocnema dobsoni (Froggatt, 1903), Lubanga et al. (2016) observed that substrate-borne vibrations vary with body size and age of males, and they are involved in the process of mate attraction, but not in mate selection.

Both insects and terrestrial isopods likely emerged in the Late Paleozoic (Broly et al. 2013) and parallelly evolved from a common aquatic pancrustacean ancestor (Regier et al. 2005, 2010; Broly et al. 2013). Therefore, similarities and differences between the two taxa at the general physiological level and in terms of behavioral mechanisms, such as communication via surface-borne vibrations, are of great interest.

To our knowledge, the role of stridulation in behavioral processes of terrestrial isopods with a stridulatory organ has never been explored before. In this study, we investigate the capability of terrestrial isopods to produce stridulations as a possible means of intra- and interspecific signaling among individuals. More specifically, we investigate the capability to use stridulation to transmit information (directly or indirectly) to conspecifics or interact with other species for different aims (e.g., defense). To this goal, we used a common Mediterranean species, Armadillo officinalis Duméril, 1816 (Crustacea: Isopoda: Oniscidea), as a model species. In this species, both capability and mechanism to produce stridulations have previously been described, but their role remains unclear. The ability of this woodlouse species to produce stridulations was first described by Verhoeff (1908) after collecting a few specimens of the species in Sicily, and, subsequently, only Caruso and Costa (1976) provided a preliminary study of stridulation in A. officinalis, in a brief article published in a local Italian journal. The species produces stridulations utilizing a ledge of scales situated on the propodus of the fourth and fifth pereopods, as has previously been described (Caruso and Costa 1976; Taiti et al. 1998). The ability to produce stridulations using a specific morphological apparatus was considered a synapomorphy of the genus Armadillo Latreille, 1802 by Schmalfuss (1996). Recently, Montesanto (2018) studied and characterized the post-marsupial manca (M) stages (equivalent to larval stages) in A. officinalis showing that the stridulatory apparatus exists from the early stages of development, namely stages M I, M II, and M III. Taiti et al. (1998) reported the presence of a similar stridulatory organ in Cubaris everesti Vandel, 1973 from Nepal, and in two other undetermined species of the same genus that belongs to the same family as Armadillo (S. Taiti, personal communication). It is thus possible that the common ancestor within the family Armadillidae had a similar stridulatory apparatus.

The biology and ethology of A. officinalis remain little known. However, the study of this species could offer broad-spectrum insights into several aspects of vibrational communication mechanisms, possibly generalizable to other 
arthropods as well. A. officinalis is a species predominantly living in Mediterranean-type ecosystems populated by various plant communities (Messina et al. 2011, 2012, 2014) in the Mediterranean basin and on the western coasts of the Black Sea (Schmalfuss 1996, 2003). These animals have mainly nocturnal habits (Vandel 1962). During the hottest hours of the day, they remain under rocks or other shelters where they form quite large aggregates, likely to prevent desiccation and predation, as reported for many terrestrial isopods (Broly et al. 2012, 2013, 2014).

In a recent study, we found statistically significant associations between the behavioral patterns of $A$. officinalis and the exposure to substrate-borne vibrations at the level of both turn alternation (Cividini and Montesanto 2018a, b) and aggregation (Cividini and Montesanto 2018c). Based on our results, adults of $A$. officinalis seem to be very reactive to substrateborne vibrations compared to both other non-stridulating species, like Armadillidium vulgare Latreille, 1804 and conspecific juveniles (Cividini and Montesanto 2018a, b). We also found a statistically significant association between the aggregative behavior of adult individuals of $A$. officinalis and exposure to substrate-borne vibrations (Cividini and Montesanto 2018c). Unlike A. vulgare (without a stridulatory apparatus), A. officinalis prevalently tends to go away from zones with higher vibrational intensity as if substrate-borne vibrations represent a source of coming danger or an adverse condition (Cividini and Montesanto 2018c). Moreover, it seems that the aggregative capability of $A$. officinalis is reduced in the presence of substrate-borne vibrations as if animals have a lower ability to localize conspecifics (Cividini and Montesanto 2018c). Currently, we do not have sufficient information on the existence of vibration-sensitive organs in terrestrial isopods. Additionally, we do not know if there is a threshold of vibrational intensity that is perceived as an alarm or as disturbance signal as described in spiders of the species Araneous sericatus Clerck, 1757 (Finck 1981). Further research is needed in this direction. However, all the above highlighted behavioral patterns seem to support the idea that terrestrial isopods with a stridulatory apparatus might have a better capability of managing substrate-borne vibrations for multiple aims (e.g., as a means of defense and intra- and interspecific communication) compared to non-stridulating ones.

This playback study aims to investigate the reaction of adult individuals of $A$. officinalis to particular vibrational stimuli, which might somehow represent potential forms of intraand interspecific signaling (relative to defense strategies as well) as previously defined. We assess whether exposure to species-specific stridulation leads $A$. officinalis to move away from the vibrational source in an attempt to clarify whether stridulations produced during conglobation triggered by predators might be perceived by a conspecific as an alert signal, thus potentially representing a possibility to anticipate danger. To better understand whether surface-borne vibrations might be perceived as an indication of a potential source of disturbance, we also aim to verify whether exposure to non-specific substrate-borne vibrations leads $A$. officinalis to move away from the vibrational source.

\section{Material and methods}

\section{Sampling and experimental design}

In April 2016, one of us (G.M.) collected numerous specimens of A. officinalis in Catania, Sicily, Italy $\left(37^{\circ} 31^{\prime} 39^{\prime \prime} \mathrm{N}\right.$ $15^{\circ} 04^{\prime} 20^{\prime \prime}$ E). Subsequently, he bred the animals at the University of Pisa, Tuscany, Italy $\left(43^{\circ} 43^{\prime} 07^{\prime \prime} \mathrm{N} 10^{\circ} 23^{\prime} 45^{\prime \prime} \mathrm{E}\right)$ in a climate chamber at a temperature of $20{ }^{\circ} \mathrm{C}$ and with a natural photoperiod. He housed them in a terrarium and fed on potato tubers and plane tree leaves (Montesanto and Cividini 2017).

In this playback study, we used a randomized controlled experimental design with a random sample of 126 adult individuals of $A$. officinalis. The strengths of this experimental design are the presence of a control group and the randomization of animals to the exposure group. Randomization allows assuming that the observed difference only depends on the exposure factor and an unknown random error, which is identical in the considered groups. The random error is due to unknown and uncontrolled factors. Before the experiment, we also checked for the bodily integrity of all the animals. The individuals were thus randomized to three different groups of exposure, consisting of 42 animals each, using a table of random numbers and a pseudorandom list of zeros, ones, and twos $(0=$ group $\mathrm{A} ; 1=$ group $\mathrm{B} ; 2=$ group $\mathrm{C})$ (Online Resource 1). Each group was exposed to different stimuli. Control group A was not exposed to any vibration type. Group B was exposed to species-specific stridulations produced by $A$. officinalis at one end of the test apparatus and nothing at the other. Group $\mathrm{C}$ was exposed to non-specific substrate-borne vibrations produced with the software Audacity (ver. 2.3.0) at one end of the test apparatus and nothing at the other (Fig. 1a).

For each animal, we evaluated both sex and molt stage (Montesanto and Cividini 2018) and measured the width of the cephalothorax (CT) in mm. Using the median value of CT $(4.209 \mathrm{~mm})$ as the central position index, animals were then categorized into two groups: smaller sizes $(<4.209 \mathrm{~mm})$ and larger sizes $(\geq 4.209 \mathrm{~mm}$ ). We categorized animals into small and large sizes because we think it is more informative to evaluate the difference at this level rather than for a one-unit increase in the CT width. Sex, animal size, and molt stage are easily measurable variables. Thus, we assessed the association of these three variables with the direction taken by animals, besides considering them as hypothetical confounders of the principal investigated association between direction taken by 


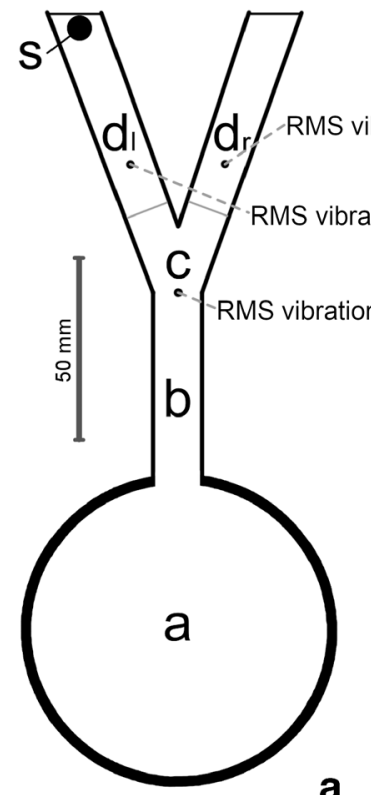

a $\quad 0.0$
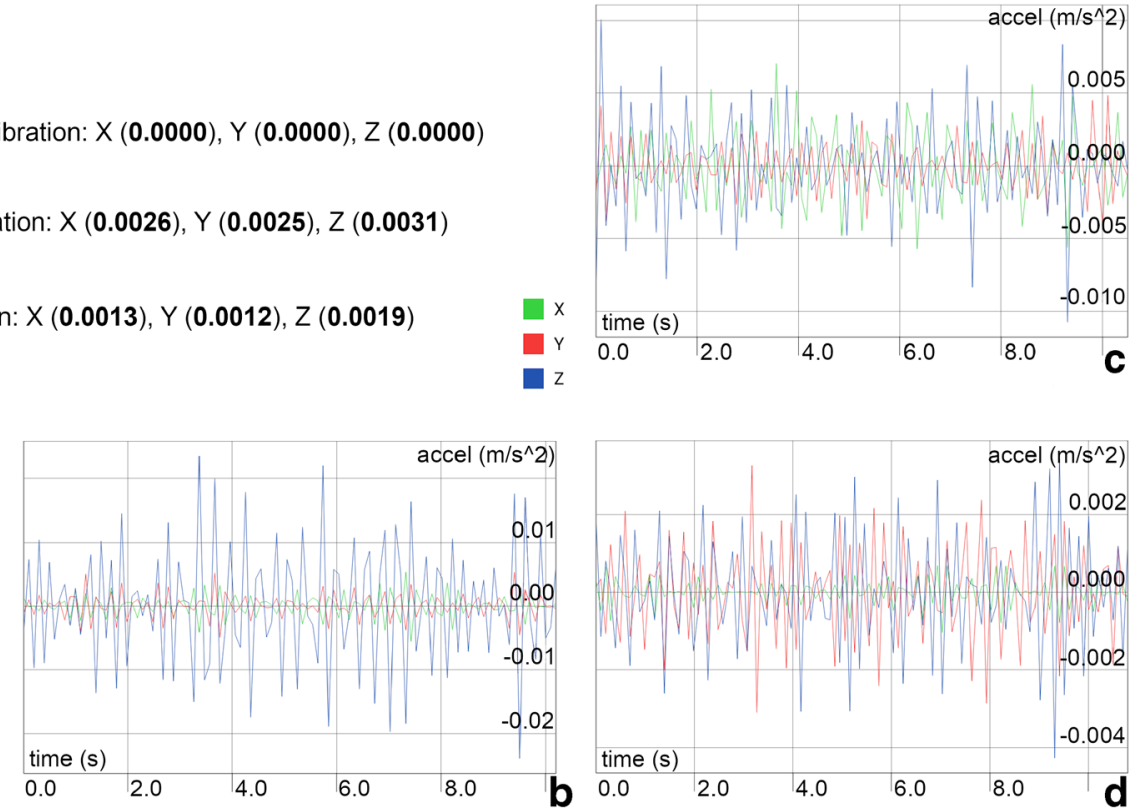

Fig. 1 Schematic drawing of the test apparatus with the measurements of the triaxial RMS vibration ( $X, Y, Z$ axes) related to the non-specific substrate-borne vibrations used in the experiment. Y-shape test apparatus: $\mathbf{s}$, position of the device used to play both Armadillo officinalis stridulations and non-specific substrate-borne vibrations; $\mathbf{a}$, starting room; b, first straight path; c, fork; $\mathbf{d}_{\mathbf{r}}$, right branch; $\mathbf{d}_{\mathbf{l}}$, left branch. a The amplitude

animals and exposure to the different vibrational stimuli, mainly based on biological considerations. Animal size can also be considered as a proxy variable for age so that its inclusion in the model might improve results (Kilada and Driscoli 2017; Montesanto and Cividini 2018).

\section{Equipment and recordings}

To test the behavior of A. officinalis, we used a Y-shape test apparatus made of high impact polystyrene (HIPS) (Fig. 1a). A moving-coil miniature earphone (MDR-EX15LP, Sony Corporation, Tokyo, Japan) was firmly fixed in place at one of the ends of the test apparatus (grey in Fig. 1a) with hot glue, set in a specific position to not interfere with the pathway of wave propagation. The earphone was well hidden from animals' sight and was used to play either species-specific stridulations or non-specific substrate-borne vibrations comparable in intensity and frequency with those generated in a natural context. Inside an "active space” (Mazzoni et al. 2014), the vibrational signal pattern is quite irregular with a non-monotonic decreasing of amplitude (Čokl 1988; Čokl et al. 2007; Mazzoni et al. 2014). Because of friction, vibrational energy decreases during propagation, with damping, distortion, and filtering mainly related to the type of waves, and the properties and geometry of the substrate (Kolsky 1964; Čokl and VirantDoberlet 2003; Cocroft and Rodriguez 2005; Cocroft et al. 2014; Mortimer 2017). Thus, for non-specific substrate-borne of the non-specific substrate-borne vibrations, calculated as the rootmean-square amplitude of the vibration data about zero (RMS vibration) was measured at the indicated points and reported on the right. b-d Levels of acceleration in $\mathrm{m} / \mathrm{s}^{2}$ of the computer-generated non-specific substrate-borne vibrations measured in a 10-s test at the points $d_{1}, c$, and $\mathrm{d}_{\mathrm{r}}$, respectively. Recordings carried out with the software VIBSENSOR vibrations, we tried to artificially simulate this natural scenario generating a random non-specific signal with the software Audacity (ver. 2.3.0) (Fig. 3). The non-specific substrate-borne vibrations were the same as those used in our previous studies (Cividini and Montesanto 2018a, b, c). The wavefunction of the species-specific stridulations and the non-specific substrateborne vibrations were analyzed in Matlab R2018b (9.5) (MathWorks Inc., Natick, MA, USA) with the Signal Analyzer App (Figs. 2 and 3) (Welch 1967; Harris 1978). The technical characteristics of the earphone used are as follows: driver unit in neodymium of $9 \mathrm{~mm}$; power handling capacity: $100 \mathrm{~mW}$; impedance: $16 \Omega$ at $1 \mathrm{kHz}$; frequency response: 8 22,000 Hz; sensitivity: $100 \mathrm{~dB} / \mathrm{mW}$; speaker diameter of $4 \mathrm{~mm}$. Both species-specific stridulations and non-specific substrateborne vibrations passed through the casing of the earphone directly to the substrate. For stridulation, we did not separate the airborne component of the signal from the accompanying surface-borne vibration. These signals are both non-stationary because their frequency content changes with time (Figs. 2 and 3 ). The spectrogram of a non-stationary signal is an estimate of the time evolution of its frequency content (Figs. 2c and 3c). The color bar indicates the power of the short-time Fourier transform in decibels. Yellow colors indicate frequency content with a higher power, and blue colors indicate frequency content with very low power (Figs. $2 \mathrm{c}$ and $3 \mathrm{c}$ ). In Fig. 2c, the strong yellow horizontal line shows the existence of a $9-\mathrm{kHz}$ tone in all the stridulation sets. 

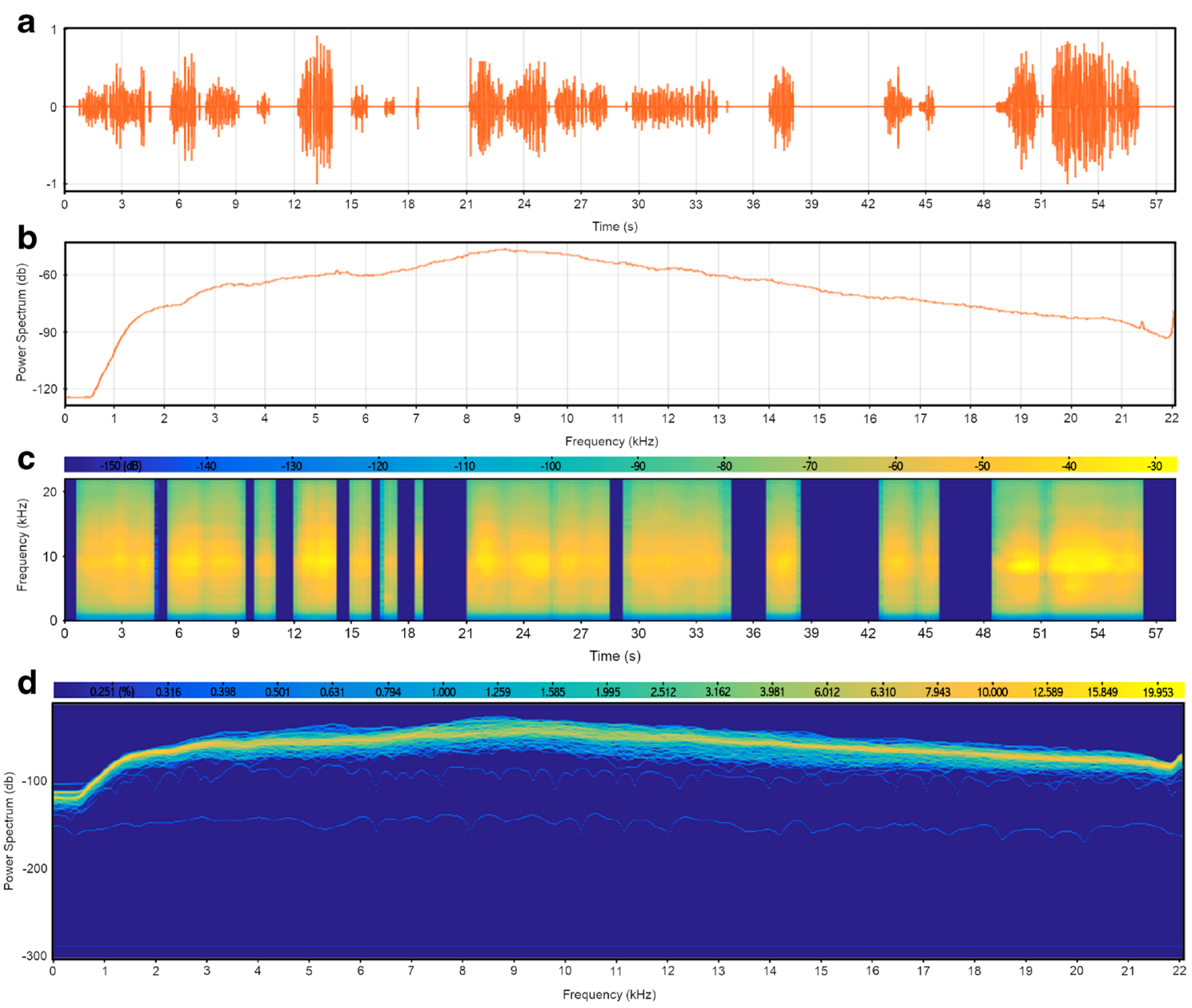

Fig. 2 Stridulations of Armadillo officinalis during conglobation: a potential form of secondary defense against predation. a Oscillogram: view of signals in the time domain. b Spectrum: view of the frequency spectrum of the signals (highest intensity reached around $9 \mathrm{kHz}$ ). c Spectrogram: view of the signals in the time-frequency domain. The spectrogram of a non-stationary signal is an estimate of the time evolution of its frequency content. The color bar indicates the power of the short-

The test apparatus was designed and tested several times to eliminate any substrate-borne vibrations from the other end of the path (as shown in Fig. 1a, position $\mathrm{d}_{\mathrm{r}}$ - RMS vibration: $X$ (0.0000), $Y(0.0000), Z(0.0001))$. To this goal, we applied foam rubber as insulation material. In Fig. $1 \mathrm{~b}-\mathrm{d}$, the vibrational diagrams show the levels of acceleration in $\mathrm{m} / \mathrm{s}^{2}$ recorded during a 10-s test with non-specific substrate-borne vibrations at the indicated points. We also reported the amplitude of the non-specific substrate-borne vibrations measured as the rootmean-square amplitude of the vibration data about zero (RMS vibration). The RMS parameter takes into account the vibration trend over time and gives a value of amplitude directly related to the energetic content of the vibration. To record the substrate-borne vibrations, we used the software VIBSENSOR (Now Instruments \& Software Inc., CA, USA) running on an Android 7.0 device (Huawei P9, with the oscilloscope inside). time Fourier transform in decibels (yellow colors are frequencies with a higher power; blue colors are frequencies with very low power). The strong yellow horizontal line shows the existence of a $9-\mathrm{kHz}$ tone in all the stridulation sets. d Persistence spectrum: a time-frequency view that shows the percentage of the time that a given frequency is present in the signal. The graphs were created using the Signal Analyzer App in Matlab R2018b (9.5) (MathWorks Inc., Natick, MA, USA)

The specimens of A. officinalis used for the stridulation recording were collected by one of us (S.S.) from olive groves in Spata-Artemida, Attiki, Greece. Subsequently, stridulations were individually recorded on a few of these specimens at a professional music-recording studio in Athens, Greece, using a high-performance microphone (Mic 451 AKG/Xpreamp, direct HD recording) produced by AKG (Harman International Industries Inc., Stamford, CT, USA ). Other technical characteristics used for the digitalization of signals are as follows: (i) digital enhancement: Bass freq RollOff, Bnrs denoise; (ii) REM: Binaural, WAV, $44100 \mathrm{~Hz}, 16 \mathrm{~b}$.

A. officinalis can produce stridulations only when assuming the typical ball-shape during the so-called conglobation or volvation. The latter mechanism seems to be used by the roller-type terrestrial isopods as a possible anti-predatory strategy. For this reason, animals were positioned on a flat surface and gently stimulated with a soft, small paintbrush to simulate 

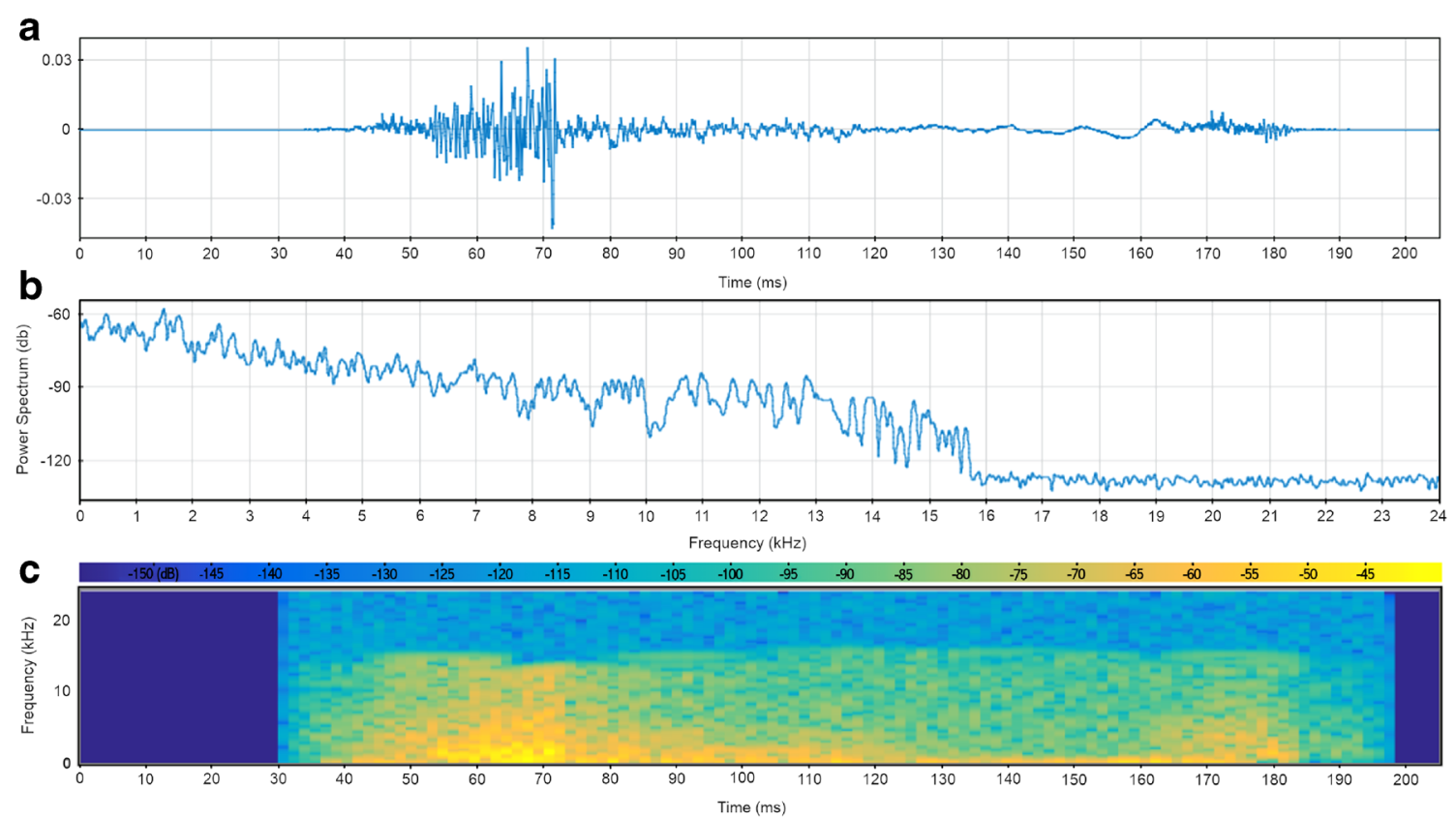

Fig. 3 Non-specific substrate-borne vibrations generated with the software Audacity (ver. 2.3.0). a Oscillogram: view of the signals in the time domain. b Spectrum: view of the frequency spectrum of the signals. c Spectrogram: view of the signals in the time-frequency domain. The spectrogram of a non-stationary signal is an estimate of the time evolution

contact with a predator and to lead them to conglobation and production of stridulations. Stridulations were recorded as sounds in the air, positioning the microphone very near the substrate, at around $1 \mathrm{~cm}$ from animals after their conglobation.

We used the freeware Audacity (ver. 2.3.0) to play the segments with the acoustic recordings of the stridulations of A. officinalis and to generate the non-specific substrate-borne vibrations according to the detailed settings given in the Appendix. The audio files were carefully inspected, checked for clipping, and saved in a WAV digital format (16-bit amplitude resolution).

\section{Experimental procedure to collect data}

We placed every animal at the open end of the test apparatus (Fig. 1a, position a), testing each individual only once. Based on the exposure group, the emission of the species-specific stridulations or the non-specific substrate-borne vibrations lasted until each animal reached one or the other of the two ends of the Y-shape test apparatus. We put no time limit, and we visually followed the animals until the completion of the test. Before each test, the test apparatus was cleaned with distilled water and $75 \%$ ethanol.

\section{Statistical and graphical analysis}

We calculated the sample size with G*Power 3.1 (Faul et al. 2009) for a multiple logistic regression according to the of its frequency content. The color bar indicates the power of the shorttime Fourier transform in decibels (yellow colors are frequencies with a higher power; blue colors are frequencies with very low power). The graphs were created using the Signal Analyzer App in Matlab R2018b (9.5) (MathWorks Inc., Natick, MA, USA)

parameters specified in Online Resource 2. A categorical variable, representing the exposure levels to vibrations, was used in the regression models in the form of dummy variables. Sex, size, and molt stage were included in the models as binary variables. Data analysis was carried out with SAS 9.4 (SAS Institute Inc., NC, USA) by using the following procedures: proc freq, proc logistic, proc glm, and other standard procedures for descriptive statistics.

Figure 1 was created using the GNU Image Manipulation Program (GIMP) (ver. 2.8.22) with the methods described by Montesanto (2015, 2016). The graphs in Figs. 2 and 3 were created with Matlab R2018b (9.5) (MathWorks Inc., Natick, MA, USA) using the Signal Analyzer App.

\section{Results}

Descriptive statistics are reported in Table 1 that summarizes the number and percentage of the animals in each group, overall and stratified by sex, size, and molt cycle stage. Overall, frequency distributions of the considered features are similar enough among the three exposure groups.

We investigated the possible association between the direction taken by adult individuals of $A$. officinalis and two different vibrational stimuli using several logistic regression models, with and without interactions. No interactions were statistically significant, and the corresponding models were not considered based on a parsimony choice. Among the models without interactions, 
Table 1 Number and percentage of the Armadillo officinalis individuals within each tested group, overall and stratified by sex, size, and molt stage

\begin{tabular}{llll}
\hline & $\begin{array}{l}\text { No vibration } \\
\text { (group A, control), } N(\%)\end{array}$ & $\begin{array}{l}\text { Species-specific stridulations } \\
\text { (group B), } N(\%)\end{array}$ & $\begin{array}{l}\text { Substrate-borne vibrations } \\
(\text { group C), } N(\%)\end{array}$ \\
\hline Males & $23(54.8)$ & $18(42.9)$ & $16(38.1)$ \\
Smaller size & $11(26.2)$ & $6(14.3)$ & $11(26.2)$ \\
Intermolt & $8(19.0)$ & $3(7.1)$ & $9(21.4)$ \\
Premolt & $3(7.1)$ & $3(7.1)$ & $2(4.8)$ \\
Larger size & $12(28.6)$ & $12(28.6)$ & $5(11.9)$ \\
Intermolt & $10(23.8)$ & $10(23.8)$ & $5(11.9)$ \\
Premolt & $2(4.8)$ & $2(4.8)$ & $0(0.0)$ \\
Females & $19(45.2)$ & $24(57.1)$ & $26(61.9)$ \\
Smaller size & $9(21.4)$ & $10(23.8)$ & $16(38.1)$ \\
Intermolt & $6(14.3)$ & $9(21.4)$ & $16(38.1)$ \\
Premolt & $3(7.1)$ & $1(2.4)$ & $0(0.0)$ \\
Larger size & $10(23.8)$ & $14(33.3)$ & $10(23.8)$ \\
Intermolt & $7(16.7)$ & $12(28.6)$ & $8(19.0)$ \\
Premolt & $3(7.1)$ & $2(4.8)$ & $2(4.8)$ \\
All animals & $42(100)$ & $42(100)$ & $42(100)$ \\
\hline
\end{tabular}

the goodness-of-fit statistics for the comparison of nested models (AIC) had very similar values. Consequently, we chose the full model as this was considered to be more informative than the reduced models from a biological point of view (Table 2). The convergence criterion was satisfied, and the Hosmer-Lemeshow goodness-of-fit test (Hosmer and Lemeshow 2000) indicated a good fit of the model to data $\left(d f=8, \chi^{2}=4.32, p=0.83\right)$. The model found statistically significant associations between the direction taken by animals and both types of vibrations. Based on our best model's results, we can thus draw the following conclusions. Individuals of $A$. officinalis exposed to species-specific stridulations have $71 \%$ lower odds, compared to non-exposed individuals of test group A (control), to move towards the direction of the stridulation source, holding all other variables constant. Individuals of $A$. officinalis exposed to non-specific substrate-borne vibrations, artificially produced with software, have about $82 \%$ lower odds, compared to non-exposed individuals of test group A (control), to move towards the direction of the source of substrate-borne vibrations, holding all other variables constant. No statistically significant association was found between the direction taken by animals and size, sex or molt stage, holding all other variables constant.

No statistically significant difference was found in the average times in seconds (log-transformed data) used for the test completion among the three groups tested (ANOVA: $d f=2, F=$ $2.83, p=0.06$; effect size $f=0.28$, obtained from the sensitivity analysis). The ANOVA model assumptions were satisfied (Shapiro-Wilk's test: $w=0.98, p=0.08$; Bartlett's test: $d f=2$, $\chi^{2}=3.02, p=0.22$ ) (Shapiro and Wilk 1965; Bartlett 1937).

No specific pattern of stridulation was identified. Nevertheless, the analysis of the single blocks of the identified signals showed that the highest intensity reached during each set of stridulation is always at around $9 \mathrm{kHz}$ before animal decreases the strength of rubbing (Fig. 2).

Our results indicate that individuals of $A$. officinalis significantly react to the presence of both types of vibrational stimuli (species-specific or non-specific), tending to avoid the vibrational source.

\section{Discussion}

We found evidence of the existence of a statistically significant association between the direction taken by A. officinalis and the presence of both species-specific stridulations and non-specific substrate-borne vibrations artificially generated by software. The vibrations generated by software are comparable in frequency and intensity with those that animals might find in their natural environment. Our results show that A. officinalis avoids the vibrational source of both types of vibrations, suggesting that these are always experienced as a source of potential danger or disturbance. These findings agree with previous observations of behavioral patterns regarding turn alternation (Cividini and Montesanto 2018a, b) and aggregation (Cividini and Montesanto 2018c), confirming the high sensitivity of A. officinalis to non-specific substrate-borne vibrations.

A. officinalis can produce stridulations utilizing a ledge of scales situated on the propodus of the fourth and fifth pereopods (Caruso and Costa 1976; Taiti et al. 1998; Montesanto 2018). These scales come into contact among them when the animal assumes a ball-shape, during the so-called conglobation or volvation, a possible form of anti-predatory 
Table 2 Results of the logistic regression model for predictors of the movement direction taken by Armadillo officinalis. $\hat{\beta}=$ parameter estimate, SE $=$ standard error, Wald $\chi^{2}=$ test statistic, $\mathrm{OR}=$ odds ratio, $95 \% \mathrm{CI}=95 \%$ confidence interval, Ref. $=$ reference group

\begin{tabular}{|c|c|c|c|c|}
\hline Predictor & $\hat{\beta}$ & $\operatorname{SE}(\hat{\beta})$ & Wald $\chi^{2}(p$ value $)$ & OR $(95 \% \mathrm{CI})$ \\
\hline Intercept & -0.67 & 0.63 & $1.15(0.28)$ & - \\
\hline \multicolumn{5}{|l|}{ Vibration type } \\
\hline Stridulations of $A$. officinalis (group B) & -1.23 & 0.50 & $6.04(0.014)$ & $0.29(0.11-0.78)$ \\
\hline Substrate-borne vibrations (group C) & -1.72 & 0.55 & $9.84(0.002)$ & $0.18(0.06-0.53)$ \\
\hline No vibration (group A, control) & Ref. & & & \\
\hline \multicolumn{5}{|l|}{ Size } \\
\hline Smaller size & 0.49 & 0.43 & $1.27(0.26)$ & $1.62(0.70-3.78)$ \\
\hline Larger size & Ref. & & & \\
\hline \multicolumn{5}{|l|}{$\operatorname{Sex}$} \\
\hline Males & -0.07 & 0.42 & $0.03(0.87)$ & $0.93(0.41-2.14)$ \\
\hline Females & Ref. & & & \\
\hline \multicolumn{5}{|l|}{ Molt stage } \\
\hline Intermolt & 0.52 & 0.56 & $0.84(0.36)$ & $1.67(0.56-5.05)$ \\
\hline Premolt & Ref. & & & \\
\hline
\end{tabular}

mechanism. The production of stridulations after conglobation might thus be an additional form of defense strategy, which is based on acoustic warning and which is put in action by $A$. officinalis to deter predators during a predation event. It is known, for instance, that many insects can produce sounds as a secondary form of defense upon contact with a predator (Masters 1979, 1980; Kowalski et al. 2014). In Coleoptera and Heteroptera, signals produced by stridulation are frequently related to defense mechanisms (Gogala 1985; Schmitt and Traue 1990; Wilson et al. 1993; Schilman et al. 2001; Serrano et al. 2003; Virant-Doberlet and Čokl 2004). In A. officinalis, this particular kind of stridulations might thus be interpreted by conspecifics as a danger signal, leading them to move away from the zone of disturbance. These stridulations might imitate other naturally occurring sounds and vibrations that could signal the presence of a predator. At this first exploratory level of study, it is still unclear which of the mechanical signals inside stridulations (i.e., acoustic or vibrational) might play a key role in the perception of the danger from conspecifics. Nevertheless, we can assume that the capability of $A$. officinalis to produce stridulations, along with its high sensitivity to surface-borne vibrations, might offer an advantage to this terrestrial isopod species. Stridulation might be an individual defense strategy, but it may also allow an individual to anticipate disturbance or injury sources inside a complex environmental signaling network.

Terrestrial isopods can use different defense strategies against predators including escape, acoustic warning, chemical secretions, specific posture, and feigning death (Schmalfuss 1984; Witz 1990; Tuf et al. 2015). Conglobation also seems to be part of the array of defense strategies associated with a specific posture, and it is used by terrestrial isopods of different families, for instance,
Armadillidae and Armadillidiidae (Tuf et al. 2015). Besides using the ability to produce stridulations during conglobation to deter a predator, the high sensitivity of $A$. officinalis to substrate-borne vibrations might help this species to put in place efficient escape strategies before encountering the predator. The capability to significantly increase the number of turn alternations as a possible defense strategy following exposure to substrate-borne vibrations, for instance, might be indicative of the fact that $A$. officinalis interprets nonspecific substrate-borne vibrations as a coming danger, or an adverse condition to avoid (Cividini and Montesanto 2018a). Predators like lycosid wolf spiders (eavesdroppers) can perceive the substrate-borne fraction of the signal produced by a planthopper (i.e., transmitter) while trying to establish a vibrational communication with a conspecific (i.e., receiver) (Hill and Wessel 2016). In the same way, a predator can accidentally produce substrate-borne vibrations, pressing its body on a solid substrate, in so alerting an unintended vibrational receiver of the danger and allowing it to escape (Hill and Wessel 2016).

In a previous study, we also found that adult individuals of A. officinalis exhibit better management of the mechanism of turn alternation, in both absence and presence of substrateborne vibrations, compared to exposed juveniles of the same species (Cividini and Montesanto 2018b). What we observed seems to indicate an improvement in the use of this potential defense strategy with age, as well as a progressive increase in reactivity to substrate-borne vibrations and a better capability to discriminate environmental signals. We also observed that adult individuals are faster than juveniles (Cividini and Montesanto 2018b). Juvenile terrestrial isopods are generally more vulnerable to predation than adults (Sunderland and Sutton 1980). At the same time, our results have undermined 
the possible role of stridulation as an aggregation stimulus, given that animals tend to move away, and not to follow the vibrational source. Cividini and Montesanto (2018c) have nevertheless speculated that other types of stridulation-like mechanical signaling, such as those produced by the reciprocal friction of animals' exoskeletons moving inside an aggregate, might be interpreted as "a call" to aggregation. Indeed, A. officinalis might be able to distinguish substrate-borne vibrations, both quantitatively and qualitatively, as a number of species of insects do (Cocroft 2001; Castellanos and Barbosa 2006; Evans et al. 2009). For instance, Cryptotermes secundus (Hill, 1925), a dry wood termite species, can distinguish the vibrational signals produced by its own conspecifics from those produced by the competitor subterranean species Coptotermes acinaciformis (Froggatt, 1898) living in the same tree, so as to avoid a lethal direct clash (Evans et al. 2009). Anyway, we still lack evidence regarding the existence of specific sensory organs in isopods, in contrast to other invertebrates, to confirm this ability of vibrational discrimination in A. officinalis. The same lack of information exists for a possible sound-perception mechanism as well, which prevents us from affirming that $A$. officinalis can perceive the acoustic component inside mechanical signals (Barth 1982; Hutchings and Lewis 1983; Kalmring 1985; Sandeman et al. 1996; Popper et al. 2001; Devetak et al. 2004).

Schmalfuss (1984) described different "ecomorphological strategies" in terrestrial isopods that are also related to defensive strategies: runners, clingers, creepers, spiny forms, rollers, as well as a few non-conformist species. Recently, S. Taiti (personal communication) has discovered some species that could be considered as jumpers. Runners are supposed to represent the plesiomorphic state (Schmidt 2008), while according to a phylogenetic analysis of the Crinocheta, the other types independently evolved several times (Schmidt 2002, 2003). The capability to produce stridulations during volvation might represent a further evolutionary step of those rollers that have a stridulatory organ, unlike most rollers that lack one (e.g., Armadillidiidae).

The study of behavioral aspects in A. officinalis and other isopod species with similar adaptations might offer broad insights into several aspects of vibrational communication mechanisms in arthropods. In this first exploratory study, we considered stridulation as a whole, without distinguishing the two different components of which it consists, that is, vibration and sound. Indeed, in the first instance, we aimed to explore the animals' reaction (if any) to the total stimulus, taking into account that nothing is still known about the possible existence of sensorial or acoustic receptors in isopods, unlike other more studied invertebrates. Given that animals were not indifferent to the stimulus, the subsequent step of our research will be to separately analyze the two components of stridulation to test which of these is mostly implicated in this behavior.
Acknowledgments Special thanks to the anonymous reviewers who checked over our manuscript for their valuable suggestions.

\section{Compliance with ethical standards}

Conflict of interest The authors declare that they have no conflict of interest.

Research involving animals All applicable international, national, and/ or institutional guidelines for the care and use of animals were followed.

\section{Appendix. Settings to generate the non-specific substrate-borne vibrations used in the experiment with the software Audacity (ver. 2.3.0)}

The option Noise was selected starting from the menu Generate.

In the window named Noise Generator, the following parameters were set:

- Noise type: Brownian

- Amplitude: 1

- Duration: 3 min

The sound was normalized at $-4.0 \mathrm{~dB}$ with the command Normalize, in the Effect menu.

Open Access This article is distributed under the terms of the Creative Commons Attribution 4.0 International License (http:// creativecommons.org/licenses/by/4.0/), which permits unrestricted use, distribution, and reproduction in any medium, provided you give appropriate credit to the original author(s) and the source, provide a link to the Creative Commons license, and indicate if changes were made.

\section{References}

Alexander RD (1957) Sound production and associated behavior in insects. Ohio J Sci 57(2):101-113 Available from: https://kb.osu.edu/ bitstream/handle/1811/4430/1/V57N02_101.pdf

Bailey W (1991) Acoustic behaviour of insects. An evolutionary perspective, Chapman and Hall, London

Barth FG (1982) Spiders and vibratory signals: sensory reception and behavioral significance. In: Witt PN, Rovner JS (eds) Spider communication. Princeton University Press, Princeton, pp 67-122

Bartlett MS (1937) Properties of sufficiency and statistical tests. Proc R Soc Lond A 160:268-282. https://doi.org/10.1098/rspa.1937.0109

Bennet-Clark HC (1999) Resonators in insect sound production: how insects produce loud pure-tone songs. J Exp Biol 202:3347-3357

Broly P, Mullier R, Deneubourg JL, Devigne C (2012) Aggregation in woodlice: social interaction and density effects. ZooKeys 176:133144. https://doi.org/10.3897/zookeys.176.2258

Broly P, Deneubourg JL, Devigne C (2013) Benefits of aggregation in woodlice: a factor in the terrestrialization process? Insectes Soc 60(4):419-435. https://doi.org/10.1007/s00040-013-0313-7 
Broly P, Devigne L, Deneubourg JL, Devigne C (2014) Effects of group size on aggregation against desiccation in woodlice (Isopoda: Oniscidea). Physiol Entomol 39:165-171. https://doi.org/10.1111/ phen. 12060

Caldwell MS, Johnston GR, McDaniel JG, Warkentin KM (2010) Vibrational signaling in the agonistic interactions of red-eyed treefrogs. Curr Biol 20:1012-1017. https://doi.org/10.1016/j.cub. 2010.03.069

Caruso D, Costa G (1976) L'apparato stridulatore e l'emissione di suoni in Armadillo officinalis Duméril (Crustacea, Isopoda, Oniscoidea). Animalia 3(1/3): 17-27

Castellanos I, Barbosa P (2006) Evaluation of predation risk by a caterpillar using substrate-borne vibrations. Anim Behav 72:461-469. https://doi.org/10.1016/j.cub.2010.03.069

Cividini S, Montesanto G (2018a) Changes in turn alternation pattern in response to substrate-borne vibrations in terrestrial isopods. Behav Proc 146:27-33. https://doi.org/10.1016/j.beproc.2017.11.005

Cividini S, Montesanto G (2018b) Differences in the pattern of turn alternation between juveniles and adults of Armadillo officinalis Dumèril, 1816 (Isopoda, Oniscidea) in response to substrate-borne vibrations. Acta Ethol 21(2):59-68. https://doi.org/10.1007/s10211018-0282-y

Cividini S, Montesanto G (2018c) Aggregative behavior and intraspecific communication mediated by substrate-borne vibrations in terrestrial arthropods: an exploratory study in two species of woodlice. Behav Proc 157:422-430. https://doi.org/10.1016/j.beproc.2018.07.006

Cocroft RB (1996) Insect vibrational defence signals. Nature 382:679680. https://doi.org/10.1038/382679a0

Cocroft RB (1998) Offspring-parent communication in subsocial insect. Dissertation, Cornell University, Ithaca, NY USA

Cocroft RB (1999) Parent-offspring communication in response to predators in a subsocial treehopper (Hemiptera: Membracidae: Umbonia crassicornis). Ethology 105:553-568

Cocroft RB (2001) Vibrational communication and the ecology of groupliving, herbivorous insects. Am Zool 41(5):1215-1221. https://doi. org/10.1093/icb/41.5.1215

Cocroft RB, Rodríguez RL (2005) The behavioral ecology of insect vibrational communication. Bioscience 55:323-334. https://doi.org/ 10.1641/0006-3568(2005)055[0323:TBEOIV]2.0.CO;2

Cocroft RB, Gogala M, Hill PSM, Wessel A (2014) Studying vibrational communication. Springer, New York

Čokl A (1988) Vibratory signal transmission in plants as measured by laser vibrometry. Period Biol 90:193-196

Čokl A, Virant-Doberlet M (2003) Communication with substrate-borne signals in small plant-dwelling insects. Annu Rev Entomol 48:29 50. https://doi.org/10.1146/annurev.ento.48.091801.112605

Čokl A, Zorovic M, Millar JG (2007) Vibrational communication along plants by the stink bugs Nezara viridula and Murgantia histrionica. Behav Proc 75:40-54. https://doi.org/10.1016/j.beproc.2007.01.003

Davranoglou L-R, Cicirello A, Taylor GK, Mortimer B (2019) Planthopper bugs use a fast, cyclic elastic recoil mechanism for effective vibrational communication at small body size. PLoS Biol 17(3):e3000155. https://doi.org/10.1371/journal.pbio.3000155

Devetak D, Pabst MA, Lipovšek Delacord A (2004) Leg chordotonal organs and campaniform sensilla in Chrysoperla Steinmann 1964 (Neuroptera): Structure and function. Denisia 13:163-171

Elias DO, Mason AC, Hoy RR (2004) The effect of substrate on the efficacy of seismic courtship signal transmission in the jumping spider Habronattus dossenus (Araneae: Salticidae). J Exp Biol 207:4105-4110. https://doi.org/10.1242/jeb.01261

Evans TA, Inta R, Lai JCS, Prueger S, Foo NW, Fu EW, Lenz M (2009) Termites eavesdrop to avoid competitors. P R Soc B, Biol Sci 276: 4035-4041. https://doi.org/10.1098/rspb.2009.1147

Ewing AW (1989) Mechanisms of sound production. In: Ewing AW (ed) Arthropod bioacoustics. Neurobiology and Behavior. Edinburgh University Press, Edinburgh, pp 16-57
Faul F, Erdfelder E, Buchner A, Lang A-G (2009) Statistical power analyses using $\mathrm{G}^{*}$ Power 3.1: Tests for correlation and regression analyses. Behav Res Methods 41:1149-1160. https://doi.org/10.3758/BRM.41.4.1149

Field LH, Bailey WJ (1997) Sound production in primitive Orthoptera from Western Australia: sounds used in defence and social communication in Ametrus sp. and Hadrogryllacris sp. (Gryllacrididae: Orthoptera). J Nat Hist 31:1127-1141

Finck A (1981) The lyriform organ of the orb-weaving spider Araneous sericatus: vibration sensitivity is altered by bending the leg. $\mathrm{J}$ Acoust Soc Am 70:231-233. https://doi.org/10.1121/1.386678

Frings H, Frings M (1958) Uses of sounds by insects. Annu Rev Entomol 3(1):87-106

Gogala M (1985) Vibrational songs of land bugs and their production. In: Kalmring K, Elsner N (eds) Acoustic and vibrational communication in insects. Paul Parey Verlag, Berlin, pp 143-150

Gogala M, Čokl A, Drašlar K, Blaževic A (1974) Substrate-borne sound communication in Cydnidae (Heteroptera). J Comp Physiol 94:2531. https://doi.org/10.1007/BF00610155

Harris FJ (1978) On the use of windows for harmonic analysis with discrete Fourier transform. P IEEE 66:51-83. https://doi.org/10. 1109/PROC.1978.10837

Haskell PT (1974) Sound production. In: Rockstein M (ed) The physiology of insect. Academic Press, Cambridge, pp 353-410

Hebets EA, Elias DO, Mason AC, Miller GL, Stratton GE (2008) Substrate-dependent signalling success in the wolf spider, Schizocosa retrorsa. Anim Behav 75(2):605-615. https://doi.org/ 10.1016/j.anbehav.2007.06.021

Hill PSM (2001) Vibration and animal communication: a review. Am Zool 41:1135-1142. https://doi.org/10.1093/icb/41.5.1135

Hill PSM (2008) Vibrational communication in animals. Harvard University Press, Cambridge MA, USA

Hill PSM (2009) How do animals use substrate-borne vibrations as an information source? Naturwissenschaften 96:1355-1371. https:// doi.org/10.1007/s00114-009-0588-8

Hill PSM, Wessel A (2016) Biotremology. Curr Biol 26:R181-R191

Hosmer DW, Lemeshow S (2000) Applied logistic regression. Wiley, New York

Howard DR, Schmidt AP, Hall CL, Mason AC (2018) Substrate-borne vibration mediates intrasexual agonism in the New Zealand Cook Strait giant weta (Deinacrida rugosa). J Insect Behav 31(6):599 615. https://doi.org/10.1007/s10905-018-9700-2

Hutchings M, Lewis B (1983) Insect sound and vibration receptors. In: Lewis B (ed) Bioacoustics: a comparative approach. Academic Press, London, pp 181-205

Kalmring K (1985) Vibrational communication in insects (reception and integration of vibratory information). In: Kalmring K, Elsner N (eds) Acoustic and vibrational communication in insects. Paul Parey, Berlin, pp 127-134

Kilada R, Driscoli J (2017) Age determination in crustaceans: a review. Hydrobiologia 799:21-36. https://doi.org/10.1007/s10750-017-3233-0

Kolsky H (1964) Stress waves in solids. J Sound Vib 1(1):88e110. https:// doi.org/10.1016/0022-460x(64)90008-2

Kowalski KN, Lakes-Harlan R, Lehmann GUC, Strauß J (2014) Acoustic defence in an insect: Characteristics of defensive stridulation and differences between the sexes in the tettigoniid Poecilimon ornatus (Schmidt 1850). Zoology 117:329-336. https://doi.org/10.1016/j. zool.2014.04.007

Lubanga UK, Peters RA, Steinbauer MJ (2016) Substrate-borne vibrations of male psyllids vary with body size and age but females are indifferent. Anim Behav 120:173-182. https://doi.org/10.1016/j. anbehav.2016.07.033

Masters WM (1979) Insect disturbance stridulation: its defensive role. Behav Ecol Sociobiol 5:187-200 https://www.jstor.org/stable/ 4599228 
Masters WM (1980) Insect disturbance stridulation: characterization of airborne and vibrational components of the sound. J Comp Physiol 135:259-268

Mazzoni V, Prešern J, Lucchi A, Virant-Doberlet M (2009) Reproductive strategy of the Nearctic leafhopper Scaphoideus titanus Ball (Hemiptera: Cicadellidae). Bull Entomol Res 99:401-413. https:// doi.org/10.1017/S0007485308006408

Mazzoni V, Lucchi A, Ioriatti C, Doberlet-Virant M, Anfora G (2010) Mating behavior of Hyalesthes obsoletus. Ann Entomol Soc Am 103:813-822. https://doi.org/10.1603/AN09145

Mazzoni V, Anfora G, Virant-Doberlet M (2013) Substrate vibrations during courtship in three Drosophila species. PLoS ONE 18: e80708. https://doi.org/10.1371/journal.pone.0080708

Mazzoni V, Eriksson A, Anfora G, Lucchi A, Virant-Doberlet M (2014) Active space and the role of amplitude in plant-borne vibrational communication. In: Cocroft RB, Gogala M, Hill PSM, Wessel A (eds) Studying vibrational communication. Springer, New York, pp 125-145

Messina G, Montesanto G, Pezzino E, Caruso D, Lombardo BM (2011) Diversity of terrestrial isopods in a protected area characterized by salty coastal ponds (Vendicari, Sicily). J Nat Hist 45:2145-2158. https://doi.org/10.1080/00222933.2011.587899

Messina G, Pezzino E, Montesanto G, Caruso D, Lombardo BM (2012) The diversity of terrestrial isopods in the natural reserve "Saline di Trapani e Paceco" (Crustacea, Isopoda, Oniscidea) in northwestern Sicily. Zookeys 176:215-230. https://doi.org/10.3897/zookeys.176.2367

Messina G, Montesanto G, Pezzino E, Sciandrello S, Caruso D, Lombardo BM (2014) Plant communities preferences of terrestrial crustaceans (Isopoda: Oniscidea) in a protected coastal area of southeastern Sicily (Italy). Biologia 69(3):354-362. https://doi.org/ 10.2478/s11756-013-0321-0

Montesanto G (2015) A fast GNU method to draw accurate scientific illustrations for taxonomy. Zookeys 515:191-206. https://doi.org/ $10.3897 /$ zookeys.515.9459

Montesanto G (2016) Drawing setae: A GNU way for digital scientific illustrations. Nauplius 24:e2016017. https://doi.org/10.1590/2358$2936 \mathrm{e} 2016017$

Montesanto G (2018) Presence of a stridulatory apparatus in the manca stages of isopods (Crustacea, Isopoda, Oniscidea). Zookeys 801: 501-518. https://doi.org/10.3897/zookeys.801.23018

Montesanto G, Cividini S (2017) A crossover design to assess feeding preferences in terrestrial isopods: a case study in a Mediterranean species. Biologia 72(2):194-203. https://doi.org/10.1515/biolog2017-0020

Montesanto G, Cividini S (2018) The moult cycle of the terrestrial isopod Armadillo officinalis Duméril, 1816 (Crustacea: Isopoda: Oniscidea). Acta Zool 99:263-273. https://doi.org/10.1111/azo.12210

Mortimer B (2017) Biotremology: do physical constraints limit the propagation of vibrational information? Anim Behav 130:165-174. https://doi.org/10.1016/j.anbehav.2017.06.015

Popper AN, Salmon N, Horch KW (2001) Acoustic detection and communication by decapod crustaceans. J Comp Physiol A 187:83-89. https://doi.org/10.1007/s003590100184

Regier JC, Shultz JW, Kambic RE (2005) Pancrustacean phylogeny: hexapods are terrestrial crustaceans and maxillopods are not monophyletic. P R Soc B 272:395-401. https://doi.org/10.1098/rspb. 2004.2917

Regier JC, Shultz JW, Zwick A, Hussey A, Ball B, Wetzer R, Martin JW, Cunningham CW (2010) Arthropod relationships revealed by phylogenomic analysis of nuclear protein-coding sequences. Nature 463:1079-1083. https://doi.org/10.1038/nature08742

Sandeman DC, Tautz J, Lindauer M (1996) Transmission of vibration across honeycombs and its detection by bee legs receptors. J Exp Biol 199:2585-2594
Schilman PE, Lazzari CR, Manrique G (2001) Comparison of disturbance stridulations in five species of triatominae bugs. Acta Trop 79:171-178. https://doi.org/10.1016/S0001-706X(01)00095-X

Schmalfuss H (1984) Eco-morphological strategies in terrestrial isopods. Symp Zool Soc 53:49-63

Schmalfuss H (1996) The terrestrial isopod genus Armadillo in western Asia (Oniscidea: Armadillidae) with descriptions of five new species. Stutt Beit Natur A 544:1-43

Schmalfuss H (2003) World catalog of terrestrial isopods (Isopoda: Oniscidea). Stutt Beit Natur A 654:1-341 Available from: http://www. oniscidea-catalog.naturkundemuseum-bw.de/Cat terr_isop.pdf

Schmidt C (2002) Contribution to the phylogenetic system of the Crinocheta (Crustacea, Isopoda). Part 1. (Olibrinidae to Scyphacidae s.str.). Mitt Mus Natur Berl Zool Reihe 78(2):275352. https://doi.org/10.1002/mmnz.20020780207

Schmidt C (2003) Contribution to the phylogenetic system of the Crinocheta (Crustacea, Isopoda). Part 2. (Oniscoidea to Armadillidiidae). Mitt Mus Natur Berl Zool Reihe 79(1):3-179. https://doi.org/10.1002/mmnz.20030790102

Schmidt C (2008) Phylogeny of the terrestrial isopoda (Oniscidea): a review. Arthropod Syst Philo 66(2):191-226

Schmitt M, Traue D (1990) Morphological and bioacoustic aspects of stridulation in Criocerinae (Coleoptera: Chrysomelidae). Zool Anz 225:225-240

Serrano AR, Diogo AC, Vicoso E, Fonseca PJ (2003) New stridulatory structures in a tiger beetle (Coleoptera: Carabidae: Cicindelinae): morphology and sound characterization. Coleopt Bull 57:161-166. https://doi.org/10.1649/538

Shapiro SS, Wilk MB (1965) An analysis of variance test for normality (complete samples). Biometrika 52(3-4):591-611. https://doi.org/ $10.2307 / 2333709$

Sunderland KD, Sutton SL (1980) A serological study of arthropod predation on woodlice in a dune grassland ecosystem. $\mathrm{J}$ Anim Ecol 49: 987-1004. https://doi.org/10.2307/4240

Taiti S, Paoli P, Ferrara F (1998) Morphology, biogeography, and ecology of the family Armadillidae (Crustacea, Oniscidea). Isr J Zool 44: 291-301. https://doi.org/10.1080/00212210.1998.10688952

Tuf IH, Drábková L, Šipoš J (2015) Personality affects defensive behaviour of Porcellio scaber (Isopoda, Oniscidea). ZooKeys 515:159 171. https://doi.org/10.3897/zookeys.515.9429

Vandel A (1962) Faune de France: 66. Isopodes terrestres (deuxième partie). Le Chevalier, Paris, pp 417-931

Verhoeff KW (1908) Über Isopoden: 15. Aufsatz. Archiv für Biontologie 2:335-387

Virant-Doberlet M, Čokl A (2004) Vibrational communication in insects. Neotrop Entomol 33:121-134. https://doi.org/10.1590/S1519$566 \times 2004000200001$

Welch PD (1967) The use of fast Fourier transform for the estimation of power spectra: a method based on time averaging over short, modified periodograms. IEEE T Acoust Speech 15:70-73

Wilson LM, Henry CS, Johnson JB, Mccaffrey JP (1993) Sound production in Phrydiuchus tau (Coleoptera, Curculionidae). Ann Entomol Soc Am 86:621-630. https://doi.org/10.1093/aesa/86.5.621

Witz BW (1990) Antipredator mechanisms in arthropods: a twenty year literature survey. Fla Entomol 73:71-99. https://doi.org/10.2307/ 3495331

Yack JE, Otero LD, Dawson JW, Surlykke A, Fullard JH (2000) Sound production and hearing in the blue cracker butterfly Hamadryas feronia (Lepidoptera, nymphalidae) from Venezuela. J Exp Biol 203:3689-3702

Young D, Bennet-Clark H (1995) The role of the tymbal in cicada sound production. J Exp Biol 198:1001-1020

Publisher's note Springer Nature remains neutral with regard to jurisdictional claims in published maps and institutional affiliations. 